\title{
Food Stress in Adelaide: The Relationship between Low Income and the Affordability of Healthy Food
}

\author{
Paul R. Ward, ${ }^{1}$ Fiona Verity, ${ }^{2}$ Patricia Carter, ${ }^{3}$ George Tsourtos, ${ }^{1}$ \\ John Coveney, ${ }^{1}$ and Kwan Chui Wong ${ }^{1}$ \\ ${ }^{1}$ Discipline of Public Health, Flinders University, Adelaide, SA 5001, Australia \\ ${ }^{2}$ School of Social and Policy Studies, Flinders University, Adelaide, SA 5001, Australia \\ ${ }^{3}$ Health Promotion Branch, Department of Health and Ageing, Adelaide, SA 5000, Australia \\ Correspondence should be addressed to Paul R. Ward; paul.ward@flinders.edu.au
}

Received 6 June 2012; Revised 6 December 2012; Accepted 13 December 2012

Academic Editor: David Strogatz

Copyright (C) 2013 Paul R. Ward et al. This is an open access article distributed under the Creative Commons Attribution License, which permits unrestricted use, distribution, and reproduction in any medium, provided the original work is properly cited.

\begin{abstract}
Healthy food is becoming increasingly expensive, and families on low incomes face a difficult financial struggle to afford healthy food. When food costs are considered, families on low incomes often face circumstances of poverty. Housing, utilities, health care, and transport are somewhat fixed in cost; however food is more flexible in cost and therefore is often compromised with less healthy, cheaper food, presenting an opportunity for families on low incomes to cut costs. Using a "Healthy Food Basket" methodology, this study costed a week's supply of healthy food for a range of family types. It found that low-income families would have to spend approximately $30 \%$ of household income on eating healthily, whereas high-income households needed to spend about $10 \%$. The differential is explained by the cost of the food basket relative to household income (i.e., affordability). It is argued that families that spend more than $30 \%$ of household income on food could be experiencing "food stress." Moreover the high cost of healthy foods leaves low-income households vulnerable to diet-related health problems because they often have to rely on cheaper foods which are high in fat, sugar, and salt.
\end{abstract}

\section{Introduction}

People in low paying jobs, particularly those who have only casual employment, are underemployed, or are on a government pension for retirement, sickness, or acting as a carer, find a range of financial stressors confronting them, the most significant for this paper being food insecurity. As in many other countries, Australian consumers have had to accommodate to increases in costs of basic food [1]. During the financial years 2007-2008 alone, overall food prices rose by $3.9 \%$, while some basic food prices rose more sharply: cheese by $14.2 \%$, milk by $12.1 \%$, poultry by $11.0 \%$, and bread by $6.8 \%$ [2]. Food cost plays a significant role in mediating food choice among low socioeconomic status (SES) groups $[1,3,4]$, who often have to cut back on food spending to make room for other essentials such as housing and utilities [5-8], leading to decreased food security [9]. This paper is predicated on the suggestion that the effects of food insecurity on families on low incomes may help to explain the higher prevalence of overweight in low-income populations.

1.1. Policy Context in Australia. Food costs jumped into the political limelight prior to the Australian 2007 federal election, with voters demanding government action to reduce prices. To honour preelection promises, the newly elected Labor government initiated a national inquiry into grocery pricing soon after taking office. However, following the release of the Grocery Pricing Inquiry Report [10] and the consequent launch of the government web site to monitor prices [11], critics considered there would be minimal, if any, impact on reducing prices $[12,13]$. This is partly because Australia is not immune to the global and economic factors and natural disasters like floods, attributing to rising costs of basic foods [14], and partly because the inquiry outcomes did nothing to actually address food costs, especially healthy food in low SES areas. 
In Australia, the National Preventative Health Taskforce (NPHT) described obesity as one of three priority action areas for better health, beside tobacco and alcohol consumption. It emphasised that addressing social inequalities in differential access to healthy food is fundamental to obesity prevention [15]. In doing so, the NPHT identified food insecurity as an important concern for low-income Australians and many at-risk groups and acknowledged the ensuing negative health consequences of inadequate access to healthy food.

Food security, within developed countries such as Australia, can be defined as the "ability of individuals, households and communities to acquire appropriate and nutritious food on a regular and reliable basis, and using socially acceptable means" [16]. Food insecurity, then, describes limited or uncertain ability to acquire appropriate foods in socially acceptable ways. This is not merely a lack of food, but also when people fear running out of food or are forced to make significant changes to their usual eating patterns due to economic constraints [17]. The 1995 National Nutrition Survey (the most up-to-date data in Australia) estimates that $5.2 \%$ of the population of Australia are "food insecure" [18].

Data collected in South Australia estimates the food insecurity rate to be higher at approximately 7\% [19]. However, this increases among at-risk groups who have lower incomes including unemployed (11.3\%), rental households (15.8\%) [18], those identifying as Aboriginal or Torres Strait Islander (23\%) [20], and recently arrived refugees (71\%) [21]. Single parents are also considered an at-risk group with reported levels of food insecurity as high as $23 \%$ [9, 17]. Diets of food insecure people are likely to lack variety and be of poor quality with lower levels of micronutrients [22-25]. Against this backdrop of rising food costs, associations between food insecurity and lower socioeconomic status, the main focus of this paper is whether people from low-income areas are less likely to consume "appropriate and nutritious food" because of poor access to healthy foods.

Adequate access to a healthy food supply is one of the major determinants of food security. In developed countries, food insecurity is associated with obesity $[17,26]$ and obesity-related disease $[27,28]$, mainly due to an increased consumption of foods high in fat and or sugar that are typically cheaper, more available, heavily marketed, and simpler to prepare than healthy alternatives [29, 30]. The health consequences of food insecurity go beyond obesity and include nutrient inadequacy [31], with lower self-reported health [27] and compromised child health [32].

\subsection{Food Costs and Food Security in Low Socioeconomic Status} Populations. There are a number of established factors differentially expose certain members of the population to periods of food insecurity and the associated consequences, including poverty [33], rising food prices in Australia [34], higher food prices, and greater density of unhealthy food options in socially disadvantaged areas $[35,36]$, other financial obligations [7], employment status [37], rurality [38], lower educational attainment [39], and lack of access to private transport [40]. A major issue identified in previous studies is that low socioeconomic status (SES) groups are, in many cases, not able to afford to purchase a wide enough range of healthy foods to maintain good health [19, 29, 41, 42]. Thus, food affordability, influenced by a range of factors, the most salient being employment status, level of education, cultural influences, and lifestyle behaviours, isolation (geographic, social, and cultural), as well as age, and disability, may affect a person's ability to access healthy food, thereby potentially compromising their nutritional status [19].

In the UK, a survey to assess the eating habits and health status of people on low incomes [43] found that they tended to consume a poorer quality diet comprising more energy dense foods such as processed meat, full fat milk, sugar, and soft drinks than those on higher incomes. They also consumed less wholemeal products and vegetables than the general population. Other studies have found that affordability of healthy foods could be a primary reason for people from low SES backgrounds not choosing healthy food $[9,19$, $38,41]$. It has also been suggested that the cost of healthier foods varies substantially from place to place $[44,45]$, thus impacting on affordability.

Food costs are not the only consideration when deciding what foods to purchase. Consumers confront increasing amounts of information on food every day and, in response, simplify food choice through coping strategies such as avoiding and favouring foods; vigilance; actively seeking and using food safety information; moderation and variety; common sense based upon previous personal experience or the experiences of significant others; or lack of concern [46]. Scientific evidence is often rejected leading to behaviour that has the potential to damage health [47]. In practice, food choice is not only driven by health concerns but also by routine; personal food preference; ethics; food cost; convenience and access; and by previous experience [48].

In addition, the taste of food is a central driver of food choice and consumption. Taste has been identified as being a significant contributor to food choice [49], particularly for younger people who have less immediate concerns with health [50]. Cultural and gender differences have been noted in the relative importance placed upon taste and health. Participants from countries such as the USA [51] and UK [52] place greater importance upon health concerns and less upon the pleasure of eating than participants in countries such as France, Belgium, and Finland [51, 52]. Likewise, women generally place less concern upon the pleasure of eating than men also demonstrating greater concern with the healthiness of food [51, 52]. A national survey of 1109 people in Australia found that $88 \%$ of respondents considered the taste of food before its price, with females and people on higher incomes more likely to do so [53]. In addition, 52\% of respondents said that they considered the price of food before its health and nutritional benefits, with males, younger people, and people with lower educational qualifications more likely to do so.

In order to study the affordability of healthy food, this study investigated the affordability of a Healthy Food Basket (HFB) in metropolitan Adelaide. A HFB is a tool commonly used to assess the cost and affordability of healthy food. The assessment was conducted in high and low household income areas of Adelaide to examine which area level effects on the cost of healthy foods. 


\section{Methods}

While there is no national Australian HFB, several HFBs have been developed in different states: the biennial Queensland Healthy Food Access Basket (QHFAB) survey [54], the periodic Illawarra Healthy Food Basket (IHFB) survey in New South Wales $[55,56]$, the Northern Territory Market Basket Survey (MBS) [57], and the South Australian survey on food cost, quality, and variety for rural areas [58]. Common features of these HFBs are the use of one standard reference family to calculate affordability and nutrient requirements based on Recommended Dietary Intakes (RDI) [59]. This limitation and its relevance to generalizing findings to a wider population have been noted [38, 44].

This study used the cross-sectional Victorian Healthy Food Basket (VHFB) survey methodology [60]. The VHFB set of methods was chosen for two key reasons: first, it uses four distinct types of reference family, developed by and considering the 2003 Family Characteristics Survey [61] and the 2001 Census of Population and Housing [62]. Second, being developed in 2007, the VHFB uses the Nutrient Reference Values (NRVs) released in 2006 instead of Recommended Daily Intakes (RDIs) to assess nutritional adequacy [63].

2.1. Choice of Locations and Types of Food Stores. For the current study, two supermarkets from the highest and lowest household income Census Collection Districts (CDs) from each Local Government Area (LGA) in metropolitan Adelaide were surveyed. A total of 61 supermarkets from 17 LGAs out of a total of 18 Adelaide LGAs were included. The City of Adelaide LGA had only two supermarkets which matched the selection criteria. Two LGAs (Prospect and Walkerville) were combined as there were only three supermarkets in each of these LGAs. The order of supermarket surveying was chosen using a random number generator. Two supermarkets refused to take part in the survey, and in each case the next supermarket on our randomized list was surveyed. When the LGA did not have enough supermarkets in the highest and/or lowest tertile CDs, adjustments were made in selection with those in the middle tertile, but closest to the extreme tertiles, being surveyed.

The supermarkets in the study were limited to the three leading supermarket chains in South Australia, Woolworths, Coles, and Foodland, based on an earlier study which indicated that families prefer to do the bulk of their food shopping in large supermarkets than in smaller corner stores, service stations, and delicatessens [40].

Specialty shops (defined as butchers and greengrocers for the purposes of this study) were also surveyed if they were located within a maximum of ten minutes walking distance of the selected supermarkets. Our inclusion of speciality shops was due to our concern that people may not "solely" buy food from supermarkets, but may also purchase from local butchers and grocers. Twenty-three supermarkets had a greengrocer and a butcher within a ten-minute walking distance, while the remaining supermarkets had either a greengrocer or a butcher (but not both), or none, of these specialty shops. In total, 27 greengrocers and 34 butchers were surveyed. For items costed in each of the different shopping venues, refer to the appendix.

2.2. Conducting the Survey. Three researchers were trained in the use of the Victorian Healthy Food Basket (VHFB) methodology and documentation tools. All data were collected within a narrow window of time in May 2009 to minimise potential seasonal variation in the price of foods.

A pilot test was conducted involving six supermarkets (two for each data collector) to assess any issues with the data collection process. The data collectors, with the rest of the research team, compared their findings, and an interrater reliability test was conducted to measure consistency across the six supermarkets surveyed and to ensure the internal consistency of the survey itself after variations in data collection had been discussed.

Out of 46 items included in the VHFB, the pilot test revealed that 38 items were clearly understood by the researchers, and the prices showed consistency across the board. Two items needed to be checked with the author of the VHFB to confirm package sizes to be surveyed. Two items needed discussion and agreement on a calculation for sizes which did not exist but were on the VHFB survey. The interrater reliability test proved to be a useful process, validating the survey as well as providing a forum for the researchers to clarify issues of difference and move to agreed principles, thereby ensuring a consistent process for conducting the survey.

After the pilot test and the necessary adjustments were made, the data collectors sought "on the spot" permission, via a letter of introduction, from the owner or manager of each specialty shop or supermarket approached, just prior to the conduct of each survey. The letter of introduction emphasized confidentiality and an assurance that no individual store would be identified. The data collection process required all food prices to be recorded on the VHFB data collection sheet.

2.3. Product Selection. The selection of products for the Healthy Food Basket (HFB) was based on the VHFB methodology $[60,64]$. Products were recorded according to the cheapest brand price in specified sizes of the food items listed in the VHFB. When the specified size was not available, the next smallest size was chosen, and the cost was multiplied upwards to match the specified size. If the next smallest size was not available, then the next largest size was selected, and the cost was multiplied downwards to match the specified size. In order to provide the cheapest but realistic HFB, generic brands were not chosen. Where a brand name was specified, only that brand of product was assessed, and if it was not available, the closest alternative was chosen. Finally, the regular price of items was used instead of special prices to reflect the standard cost of the HFB.

2.4. Reference Families. This study examined four household types of reference families, including a "typical" family (two parents plus two dependents), a single-parent family (one parent plus two dependents), a single adult, and an elderly 
retired pensioner. The reference families were the same as those used in the VHFB [60].

Many Healthy Food Basket surveys only take a limited household range into account when comparing costs. For example, the Illawarra HFB looks exclusively at a family of six. This study has the flexibility to look at a range of family types, providing a more tailored view of what it actually costs for different family or household types. The variations in affordability according to household type and income has proved to be very revealing especially when examining the cost of a Healthy Food Basket for people on welfare benefits (single adult on a government pension).

2.5. Assessment of Affordability. The cost of the basket was calculated for each reference family and priced according to the guidelines in the VHFB survey [60]. Affordability of the HFB was defined as the cost of the HFB as a percentage of household income. Two kinds of incomes were used to measure affordability. The first was based on government welfare payments for unemployed families (Table 1), while the second was based on Equivalised Disposable Household Income (EDHI) for South Australia (SA) 2005/2006 [65], which was adjusted to current values using Wage Price Index [66] rises since 2005/2006 (Table 2). The study assumes that high-EDHI households shopped in supermarkets in highincome areas and low-EDHI households in supermarkets in low-income areas.

2.6. Data Analysis. The data were analyzed with SPSS v17.0 for Windows (SPSS Inc., Chicago, IL, USA). Cost and affordability of the HFB were calculated for each reference family. Mean (standard error of the mean:mean (SE)) costs were compared between supermarkets in high- and low-income areas using the $t$-test. Affordability was calculated as a mean (SE) for high and low EDHI, assuming that high-EDHI families shopped in high-income household income areas and vice versa. Affordability for welfare payment receiving families was calculated as cost of the HFB as a proportion of income mean (SE) for each family type. Significance was taken as $P \leq 0.05$.

\section{Results}

3.1. Cost of the Healthy Food Basket (HFB). The mean cost (SD) of the HFB items sourced exclusively from supermarkets showed no statistically significant difference between highand low-SES areas. When sourced from both supermarkets and specialty shops (greengrocers and butchers), again the data shows no statistically significant difference between an HFB from high- and low-SES areas.

These findings demonstrate that geographic location of supermarkets and speciality shops across metropolitan Adelaide does not appear to impact on the cost of the HFB. Our findings indicate, instead, that family type and income have the most significant impact in terms of the affordability of the HFB and therefore on food security. In other words, access to and affordability of healthy food supplies in metropolitan Adelaide are not so much dependent on relationship between
TABLE 1: Australian government welfare benefit payments ${ }^{\mathrm{a}}$ (as of May 2009) per fortnight according to family type.

\begin{tabular}{lccc}
\hline Typical family & $\begin{array}{c}\text { Single-parent } \\
\text { family }\end{array}$ & $\begin{array}{c}\text { Elderly retired } \\
\text { pensioner }\end{array}$ & Single adult \\
\hline$\$ 1253.50$ & $\$ 975.88$ & $\$ 569.80$ & $\$ 453.30$ \\
\hline
\end{tabular}

${ }^{a}$ Australian government welfare benefit payments are paid to people who are either unemployed and looking for work, on disability payments, retired from employment, unemployed single-parent families, on sickness allowance, or on carer's allowance.

Note: data extracted from Department of Human Services-Centrelink site at: http://www.centrelink.gov.au/.

TABle 2: Adjusted ${ }^{\mathrm{a}}$ Equivalised Disposable Household Income for extreme tertiles per fortnight according to family type $\mathrm{b}^{\mathrm{b}}$.

\begin{tabular}{lccc}
\hline & Typical family & Single parent family & Single adult \\
\hline Lowest tertile & $\$ 1457.53$ & $\$ 1110.50$ & $\$ 694.06$ \\
Highest tertile & $\$ 4664.08$ & $\$ 3553.59$ & $\$ 2220.99$ \\
\hline
\end{tabular}

${ }^{a}$ Adjusted for Wage Price Index from 2005/2006 to March 2009.

${ }^{b}$ Data for elderly retired pensioner was not included as all elderly were assumed not to receive any income except welfare payments.

Note: data extracted from Australian Bureau of Statistics figures not in the public realm.

location of shop (whether they are in high- or low-SES areas) as on the location of people on a social strata in relation to income.

Further data revealed that, from supermarkets only, the "typical" family in high-income areas would need to spend on average $8.9 \%$ of income on the HFB, while families in low-income areas would need to spend $28.3 \%$ of income. Thus people on low incomes would need to spend at least three times as much in terms of proportion of income as the amount spent by people on high incomes. Similar proportions between low and high income were obtained for the other reference family types (e.g., single-parent family: $25.6 \%$ versus $8.0 \%$; single adult $18.6 \%$ versus $5.9 \%$ ). As well, the "typical" family would need to spend more, as a proportion of income, than the other family types $(8.9 \%$ to $28.3 \%$ of income), with the single adult spending the least, as a proportion $(5.9 \%$ to $18.6 \%)$. These figures were almost identical when the HFB was costed in supermarkets plus specialty shops.

For families receiving welfare benefits, the proportion of income that would need to be spent on the HFB ranged from $17 \%$ to $34 \%$ of income. The "typical" family on welfare benefits would need to spend a larger proportion of their income on the HFB (33.0\%) than the other family types (single parent family $29.1 \%$ and single adult $28.6 \%$ ). The "elderly retired pensioner" on benefits would spend the smallest proportion (17.4\%). It appears that the more people within a household, the higher the proportion of the welfare payments that would need to be spent to afford the HFB, suggesting that the welfare payment does not accommodate the increased family size in relation to the cost of the HFB. There was no statistically significant difference between the percentage of income that would need to be spent on the HFB 
when obtained from supermarkets or from supermarkets and specialty shops.

Pearson's correlations were then conducted between variables relating to the affordability for the different family types at both supermarkets and combined supermarkets and specialty shops. Very high correlation coefficients were found (between 0.88 and $0.99, P<0.0001$ ). Essentially, the Pearson's correlation found no difference in the affordability between supermarkets and combined supermarkets and specialty shops.

Finally an error bar (Figure 1) was developed from the data which demonstrates that there is a clear distinction between values for family types in high-SES areas and the same family types in low-SES areas. More significantly, Figure 1 shows that the affordability of healthy food, as a proportion of income, differs according to family type. Regardless of socioeconomic status, the data points to healthy food becoming less affordable as the number of family members increases: healthy food is most affordable for a single adult, then a single parent with two dependents and is most expensive (least affordable as a proportion of income) for the typical family (two adults and two children).

\section{Discussion}

The findings showed that healthy food was significantly less affordable for families on low incomes where up to $28 \%$ of income would need to be spent to afford the HFB compared to high-income families (6\% to $9 \%$ ). On average, families in the lowest tertile earned approximately one third of the income of people in the highest tertile, explaining the difference in affordability between low- and high-income families.

For families on welfare payments, the situation was even worse. Excluding elderly pensioners, the percentage of income that would need to be spent on the HFB for the typical family, single-parent family, and single adult was 33.0\%, $29.1 \%$, and $28.6 \%$, respectively. Similar results have been found in previous studies conducted in Adelaide [44], rural South Australia [38] and in the Illawarra region of New South Wales [67]. These findings suggest that in order to purchase a HFB, both low-income families and families on welfare payments would need to spend significantly more than the $17 \%$ average expenditure on food by Australian households.

The findings also indicate that larger families have less income to be able to afford a healthy diet. Therefore, it appears that while a single person has to spread one income over a single person, a typical family (two parents plus two dependents) has to spread their two incomes over four people. This becomes another affordability factor, particularly for those "typical" families who may have only one income, or two low incomes. This "food stress" is a product of the cost of healthy food relative to the income of the household and is not due to the lack of access to healthy food. For lowincome families and households this phenomenon cannot be separated from "housing stress," occurring when households spend $30 \%$ or more of their income on housing costs [68-70]. The approximately $30 \%$ of income required to eat healthily (i.e., on the basis of the HFB) means that families on welfare

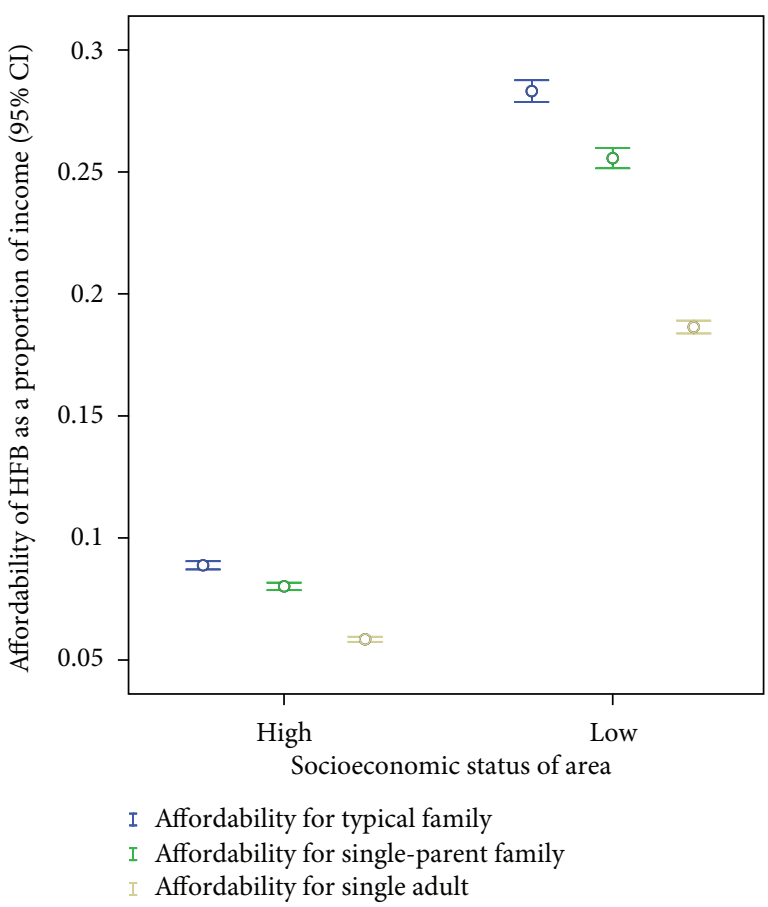

FIGURE 1: Affordability for different family types by SES.

payments may spend up to $60 \%$ of their welfare income on food and rent (or mortgage payments) before paying bills, transportation costs, educational costs for children, and medical expenses [71].

Such a scenario provides further understanding of the reasons why, in order to save money for other basic needs, families on low incomes tend to choose cheaper foods, which are often energy dense and nutrient poor $[29,72,73]$. Given the overall costs that families on low incomes face and given that housing is generally a fixed cost, low-income households are likely to attempt to save money on food, which is not a fixed cost, resulting in the purchase of unhealthy, energy dense, less expensive foods. This explains why people on low incomes inhabit an environment which may be classified as "obesogenic" for the simple reason that few healthy consumption options are open to them. It follows that educational messages alone aimed at the public about healthy eating will not change the unhealthy eating habits of people on low incomes who cannot afford to spend up to one third of their income to purchase a healthy diet. Reducing the price of healthy foods and raising welfare payments in the context of a national social policy framework could be the most direct and efficient ways to solve this issue [74]. Unaffordable healthy food on top of housing stress has serious consequences for health and wellbeing for low-income households.

4.1. Strengths and Limitations of the Study. One of the assumptions in this study was that people will shop at their local supermarket. There is some evidence from the USA that people on low incomes are willing to travel beyond their local food store in order to buy food, but this travel distance was between 1 to 1.5 miles [75]. However, research undertaken 
TABLE 3: Components of healthy food basket costed in various shopping venues.

\begin{tabular}{|c|c|c|c|c|}
\hline Basket items & Product size & $\begin{array}{c}\text { Costed in } \\
\text { supermarkets }\end{array}$ & $\begin{array}{c}\text { Costed in specialty } \\
\text { shops (greengrocers) }\end{array}$ & $\begin{array}{c}\text { Costed in specialty } \\
\text { shops (butchers) }\end{array}$ \\
\hline \multicolumn{5}{|l|}{ Cereal group } \\
\hline White bread & $650 \mathrm{~g}$ & $\mathrm{X}$ & & \\
\hline Wholemeal bread & $650 \mathrm{~g}$ & $\mathrm{X}$ & & \\
\hline Crumpets (rounds) & $300 \mathrm{~g}$ & $\mathrm{X}$ & & \\
\hline Weet-bix & $750 \mathrm{~g}$ & $\mathrm{X}$ & & \\
\hline Instant oats & $500 \mathrm{~g}$ & $\mathrm{X}$ & & \\
\hline Pasta & $500 \mathrm{~g}$ & $\mathrm{X}$ & & \\
\hline White rice & $1 \mathrm{~kg}$ & $\mathrm{X}$ & & \\
\hline Instant noodles & $85 \mathrm{~g}$ & $\mathrm{X}$ & & \\
\hline Premium biscuits & $250 \mathrm{~g}$ & $\mathrm{X}$ & & \\
\hline \multicolumn{5}{|l|}{ Fruit } \\
\hline Apples & Per $1 \mathrm{~kg}$ & $\mathrm{X}$ & $\mathrm{X}$ & \\
\hline Oranges & Per $1 \mathrm{~kg}$ & $\mathrm{X}$ & $\mathrm{X}$ & \\
\hline Bananas & Per $1 \mathrm{~kg}$ & $\mathrm{X}$ & $\mathrm{X}$ & \\
\hline Tinned fruit salad, natural juice & $450 \mathrm{~g}$ & $\mathrm{X}$ & & \\
\hline Sultanas & $375 \mathrm{~g}$ & $\mathrm{X}$ & & \\
\hline Orange juice (100\%) NAS & $2 \mathrm{~L}$ & $\mathrm{X}$ & & \\
\hline \multicolumn{5}{|l|}{ Vegetables, legumes } \\
\hline Tomatoes & Per $1 \mathrm{~kg}$ & $\mathrm{X}$ & $\mathrm{X}$ & \\
\hline Potatoes & Per $1 \mathrm{~kg}$ & $\mathrm{X}$ & $\mathrm{X}$ & \\
\hline Pumpkin & Per $1 \mathrm{~kg}$ & $\mathrm{X}$ & $\mathrm{X}$ & \\
\hline Cabbage & Half & $\mathrm{X}$ & $\mathrm{X}$ & \\
\hline Lettuce & Whole & $\mathrm{X}$ & $\mathrm{X}$ & \\
\hline Carrots & Per $1 \mathrm{~kg}$ & $\mathrm{X}$ & $\mathrm{X}$ & \\
\hline Onions & Per $1 \mathrm{~kg}$ & $\mathrm{X}$ & $\mathrm{X}$ & \\
\hline Frozen peas & Per $1 \mathrm{~kg}$ & $\mathrm{X}$ & & \\
\hline Tinned tomatoes & $400 \mathrm{~g}$ & $\mathrm{X}$ & & \\
\hline Tinned beetroot & $450 \mathrm{~g}$ & $\mathrm{X}$ & & \\
\hline Tinned corn kernels & $440 \mathrm{~g}$ & $\mathrm{X}$ & & \\
\hline Tinned baked beans & $420 \mathrm{~g}$ & $\mathrm{X}$ & & \\
\hline \multicolumn{5}{|l|}{ Meat and alternatives } \\
\hline Fresh bacon, short cut, rindless & Per $1 \mathrm{~kg}$ & $\mathrm{X}$ & & $\mathrm{X}$ \\
\hline Fresh ham & Per $1 \mathrm{~kg}$ & $\mathrm{X}$ & & $\mathrm{X}$ \\
\hline Beef mince, regular & Per $1 \mathrm{~kg}$ & $\mathrm{X}$ & & $\mathrm{X}$ \\
\hline Lamb chops, forequarter & Per $1 \mathrm{~kg}$ & $\mathrm{X}$ & & $\mathrm{X}$ \\
\hline Chicken fillets, skin off & Per $1 \mathrm{~kg}$ & $\mathrm{X}$ & & $\mathrm{X}$ \\
\hline Sausages, thin beef & Per $1 \mathrm{~kg}$ & $\mathrm{X}$ & & $\mathrm{X}$ \\
\hline Large eggs (min $50 \mathrm{~g}$, caged) & $700 \mathrm{~g}$ dozen & $\mathrm{X}$ & & $\mathrm{X}$ \\
\hline Tinned tuna (unsat. oil) & $425 \mathrm{~g}$ & $\mathrm{X}$ & & \\
\hline Tinned salmon, pink (water) & $210 \mathrm{~g}$ & $\mathrm{X}$ & & \\
\hline \multicolumn{5}{|l|}{ Dairy } \\
\hline Fresh full-cream milk & $1 \mathrm{~L}$ & $\mathrm{X}$ & & \\
\hline Fresh reduced-fat milk & $2 \mathrm{~L}$ & $\mathrm{X}$ & & \\
\hline Reduced-fat flavoured yoghurt & $1 \mathrm{~kg}$ tub & $\mathrm{X}$ & & \\
\hline Full-fat long-life milk & $1 \mathrm{~L}$ & $\mathrm{X}$ & & \\
\hline Cheese, block & $500 \mathrm{~g}$ & $\mathrm{X}$ & & \\
\hline
\end{tabular}


TABLE 3: Continued.

\begin{tabular}{|c|c|c|c|c|}
\hline Basket items & Product size & $\begin{array}{c}\text { Costed in } \\
\text { supermarkets }\end{array}$ & $\begin{array}{c}\text { Costed in specialty } \\
\text { shops (greengrocers) }\end{array}$ & $\begin{array}{l}\text { Costed in specialty } \\
\text { shops (butchers) }\end{array}$ \\
\hline \multicolumn{5}{|l|}{ Noncore foods } \\
\hline Polyunsaturated margarine & $500 \mathrm{~g}$ & $\mathrm{X}$ & & \\
\hline White sugar & $1 \mathrm{~kg}$ & $\mathrm{X}$ & & \\
\hline Canola oil & $750 \mathrm{~mL}$ & $\mathrm{X}$ & & \\
\hline
\end{tabular}

in Adelaide found that supermarkets were the main source of food shopping and that most people shop at one of their most local supermarkets $[40,76]$. Nevertheless, whilst we assumed that people who live in a particular area are likely to also purchase food from their local supermarket, this may not always be the case.

It may also be the case that, in addition to the lack of affordability of healthy food for low income families, they may have to travel further to find supermarkets or other shops that stock healthy food, thereby adding a doubledisadvantage associated with "food stress." Our study did not examine the occurrence of the so-called "food deserts" in Adelaide, although they have been found in other Western countries [77-81]. Further research is needed in Australia to examine the nature and extent of food deserts, particularly in low-income areas.

This study used HFBs as a "hypothetical" shopping list which, if purchased, would provide the necessary nutrition for the different reference families. In many studies using HFBs, methods are often not well described, and the rationale for and composition of the HFBs vary greatly. The constituents of the HFBs are meant to reflect the nutritional needs of population groups. However, some HFBs only use fruits and vegetables as a proxy for healthy foods whereas other HFBs are based on current food purchasing patterns obtained from household food surveys, which may not represent healthy food on the basis of nutritional guidelines [34, 82]. Some studies investigating the costs of HFBs have tried to be pragmatic by including healthier variations of popularly consumed foods [83-86] that do not attempt to encompass total dietary requirements. It has been argued that whilst these may be potentially more realistic in terms of what consumers may purchase, most appear to be quite subjective [83]. The HFB used on this paper was based on the Australian national nutritional guidelines and therefore represents the required nutrients to constitute a healthy diet.

In addition, HFBs may be criticized for being generic, and thus not necessarily encompassing healthy foods eaten as part of different culturally appropriate diets. For example, the range of vegetables eaten by different new migrant groups in Australia is not captured in the HFB, some of which may need to be purchased from speciality stores or home grown. We recognise this limitation of HFBs and suggest that further work needs to be undertaken to adapt HFBs to the culturally specific needs of particular new migrant groups. However, the HFB used in this paper was developed to represent the different dietary needs of different hypothetical reference families/households of various compositions and therefore attempts to understand the differential food affordability issues for such family types.

A key strength of our study is that we took into account data across the entire Adelaide metropolitan area (although two LGAs were collapsed into one due to small numbers of supermarkets in two of the LGAs). The previous HFB study in Adelaide [44] involved only five Local Government Areas (LGAs). However, this study has allowed us to examine patterns over the entire 18 LGAs of metropolitan Adelaide.

A further potential limitation of HFBs is that the prices of fresh food items in the HFB fluctuate during the year according to season and supply. While a one-time point measurement may not represent the average price of these food items, the HFB is a monitoring tool, and the fruit and vegetable items included in the HFB are generally available all year round. Given that food prices have been rising overall, there is value in establishing an ongoing monitoring system for South Australia to assist in assessing changes in the affordability of healthy food over time, as is the case currently in Queensland and the Northern Territory. Continuous measurement of the HFB would assist in developing an overall price index. Such an index could be used to compare changes in cost with income over time which would allow for the monitoring of the affordability of the HFB and would thereby lead to a greater understanding of the dynamic nature of food affordability over time.

\section{Conclusion}

Overall, affordability was a significant issue for families on low incomes in comparison to high-income families. The evidence come out of this study shows that the purchase of the HFB would create significant "food stresses" for families on welfare payments and low incomes. On top of housing stress that is already experienced by this population group, many of these people find themselves in extremely difficult economic circumstances. The food security and obesity literature, referred to earlier in this paper, points to the same associations, where lack of income is a barrier to purchasing healthy foods and correlated with overweight and obesity. The findings arising from this study solidify the link between income and cost resulting in "food stress" for people on low incomes. When linked to "housing stress," it could be argued that people will scrimp on the more expensive healthy foods and spend more on the cheaper, often energy dense nutrient poor foods. These trends are also supported by previous work conducted by the authors of this paper in which a link was 
made between food insecurity and obesity [19]. Overall, this study has provided a valuable insight into the links between food cost and income and therefore food affordability.

\section{Appendix}

See Table 3.

\section{Acknowledgments}

The authors would like to thank the managers and/or owners of supermarkets, butchers, and greengrocers who participated in this study. They thank Dr. Robert Muller, formerly at Flinders University for data collection, Ms. Claire Palermo, Faculty of Medicine Nursing and Health Sciences, Monash University for advice on methodology, and SA Health for funding the project. Special thanks to Trish Clark for administrative support and to Hannah Reichstein and Pei Qi Ho for assisting with data collection. They would like to thank the nutrition and dietetics students for collecting the healthy food basket data. They would also like to thank Dr. Robert Muller for his contribution to organising the data collection. This study was funded by the South Australian Department of Health.

\section{References}

[1] M. S. Harrison, T. Coyne, A. J. Lee et al., "The increasing cost of the basic foods required to promote health in Queensland," Medical Journal of Australia, vol. 186, no. 1, pp. 9-14, 2007.

[2] Australian Bureau of Statistics, "Consumer price index Australia: June quarter 2008," July 2008, http://www.ausstats.abs .gov.au/ausstats/subscriber.nsf/0/8D94183E5AB6CA19CA25748E0012B013/\$File/64010_jun\%202008.pdf.

[3] G. Turrell, B. Hewitt, C. Patterson, B. Oldenburg, and T. Gould, "Socioeconomic differences in food purchasing behaviour and suggested implications for diet-related health promotion," Journal of Human Nutrition and Dietetics, vol. 15, no. 5, pp. 355-364, 2002.

[4] P. Monsivais, A. Aggarwal, and A. Drewnowski, "Are socioeconomic disparities in diet quality explained by diet cost?" Journal of Epidemiology and Community Health, vol. 66, pp. 530-535, 2012.

[5] S. Booth and A. Smith, "Food security and poverty in Australia-challenges for dietitians," Australian Journal of Nutrition and Dietetics, vol. 58, no. 3, pp. 150-156, 2001.

[6] N. Wrigley, D. Warm, B. Margetts, and M. Lowe, "The Leeds "food deserts" intervention study: what the focus groups reveal," International Journal of Retail \& Distribution Management, vol. 32, no. 2, pp. 123-136, 2004.

[7] S. I. Kirkpatrick and V. Tarasuk, "Adequacy of food spending is related to housing expenditures among lower-income Canadian households," Public Health Nutrition, vol. 10, no. 12, pp. 14641473, 2007.

[8] J. Douglas, "Food insecurity in Northern Adelaide," in SACOSS News, chapter 8, SACOSS, Adelaide, Australia, 2006.

[9] I. Law, P. Ward, and J. Coveney, "Food insecurity in South Australian single parents: a livelihoods framework approach," Critical Public Health, vol. 21, no. 4, pp. 455-469, 2011.
[10] Commonwealth of Australia, Report of the ACCC Inquiry into the Competitiveness of Retail Prices for Standard Groceries, Australian Competition and Consumer Commission, Canberra, Australia, 2008.

[11] Commonwealth of Australia, "GROCERYchoice," 2008, http:// www.acc..gov.au/content/index.phtml/itemId/847778/.

[12] "Government in a spin while Australian retailing comes up trumps-retail response to ACCC Grocery Prices Inquiry," 2008, http://www.getfarming.com.au/pages/farming/articles_ view.php?fId=9200020080808141316.

[13] J. Irvine, "Rudd price check: he's powerless," in Sydney Morning Herald, Fairfax, Sydney, Australia, 2008.

[14] A. Stoeckel, High Food Prices: Causes, Implications and Solutions, Rural Industries Research and Development Corporation, Editor, Australian Government, Canberra, Australia, 2008.

[15] National Preventative Health Taskforce, "Australia: the healthiest country by 2020," Discussion Paper, Commonwealth of Australia, Canberra, Australia, 2008.

[16] L. Rychetnik, K. Webb, L. Story, and T. Katz, Food Security Options Paper: A Planning Framework and Menu of Options for Policy and Practice Interventions, NSW Centre for Public Health Nutrition, Sydney, Australia, 2003.

[17] C. Burns, A Review of the Literature Describing the Link between Poverty, Food Insecurity and Obesity with Specific Reference to Australia, VicHealth, Victoria, Australia, 2004.

[18] G. Marks et al., Key Food and Nutrition Data for Australia 1990-1999, Commonwealth of Australia, Canberra, Australia, 2001.

[19] W. Foley, P. Ward, P. Carter, J. Coveney, G. Tsourtos, and A. Taylor, "An ecological analysis of factors associated with food insecurity in South Australia, 2002-7," Public Health Nutrition, vol. 13, no. 2, pp. 215-221, 2010.

[20] C. Shannon, "Acculturation: aboriginal and torres strait islander nutrition," Asia Pacific Journal of Clinical Nutrition, vol. 11, supplement 3, pp. S576-S578, 2002.

[21] D. Gallegos, P. Ellies, and J. Wright, "Still there's no food! Food insecurity in a refugee population in Perth, Western Australia," Nutrition and Dietetics, vol. 65, no. 1, pp. 78-83, 2008.

[22] NSW Centre for Public Health Nutrition, Food Security Options Paper: A Planning Framework and Menu of Options for Policy and Practice Interventions, NSW Department of Health \& The University of Sydney, Sydney, Australia, 2003.

[23] C. M. Champagne, P. H. Casey, C. L. Connell et al., "Poverty and food intake in rural America: diet quality is lower in food insecure adults in the Mississippi Delta," Journal of the American Dietetic Association, vol. 107, no. 11, pp. 1886-1894, 2007.

[24] V. Tarasuk, L. Mcintyre, and J. Li, "Low-income women's dietary intakes are sensitive to the depletion of household resources in one month," Journal of Nutrition, vol. 137, no. 8, pp. 1980-1987, 2007.

[25] A. M. Hamelin, M. Beaudry, and J. P. Habicht, "Characterization of household food insecurity in Québec: food and feelings," Social Science and Medicine, vol. 54, no. 1, pp. 119-132, 2002.

[26] K. S. Martin and A. M. Ferris, "Food insecurity and gender are risk factors for obesity," Journal of Nutrition Education and Behavior, vol. 39, no. 1, pp. 31-36, 2007.

[27] N. T. Vozoris and V. S. Tarasuk, "Household food insufficiency is associated with poorer health," Journal of Nutrition, vol. 133, no. 1, pp. 120-126, 2003. 
[28] H. K. Seligman, A. B. Bindman, E. Vittinghoff, A. M. Kanaya, and M. B. Kushel, "Food insecurity is associated with diabetes mellitus: results from the National Health Examination and Nutrition Examination Survey (NHANES) 1999-2002," Journal of General Internal Medicine, vol. 22, no. 7, pp. 1018-1023, 2007.

[29] A. Drewnowski and S. E. Specter, "Poverty and obesity: the role of energy density and energy costs," American Journal of Clinical Nutrition, vol. 79, no. 1, pp. 6-16, 2004.

[30] K. C. Wong, J. Coveney, P. Ward et al., "Availability, affordability and quality of a healthy food basket in Adelaide, South Australia," Nutrition and Dietetics, vol. 68, no. 1, pp. 8-14, 2011.

[31] S. I. Kirkpatrick and V. Tarasuk, "Food insecurity is associated with nutrient inadequacies among Canadian adults and adolescents," Journal of Nutrition, vol. 138, no. 3, pp. 604-612, 2008.

[32] K. Alaimo, C. M. Olson, E. A. Frongillo, and R. R. Briefel, "Food insufficiency, family income, and health in US preschool and school-aged children," American Journal of Public Health, vol. 91, no. 5, pp. 781-786, 2001.

[33] D. Polit, A. London, and J. Martinez, Food Security and Hunger in Poor, Mother-Headed Families in Four U.S. Cities. The Project on Devolution and Urban Change Working Paper, Manpower Demonstration Research Corporation, New York, NY, USA, 2000.

[34] M. S. Harrison, T. Coyne, A. J. Lee et al., "The increasing cost of the basic foods required to promote health in Queensland," Medical Journal of Australia, vol. 186, no. 1, pp. 9-14, 2007.

[35] A. J. M. Donkin, E. A. Dowler, S. J. Stevenson, and S. A. Turner, "Mapping access to food in a deprived area: the development of price and availability indices," Public Health Nutrition, vol. 3, no. 1, pp. 31-38, 2000.

[36] A. Ellaway and S. Macintyre, "Shopping for food in socially contrasting localities," British Food Journal, vol. 102, pp. 52-59, 2000.

[37] L. Mcintyre, "Food security: more than a determinant of health," Policy Options, vol. 24, no. 3, pp. 46-51, 2003.

[38] P. R. Ward, J. Coveney, F. Verity, P. Carter, and M. Schilling, "Cost and affordability of healthy food in rural South Australia," Rural and Remote Health, vol. 12, p. 1938, 2012.

[39] G. Turrell and A. M. Kavanagh, "Socio-economic pathways to diet: modelling the association between socio-economic position and food purchasing behaviour," Public Health Nutrition, vol. 9, no. 3, pp. 375-383, 2006.

[40] J. Coveney and L. A. O’Dwyer, "Effects of mobility and location on food access," Health and Place, vol. 15, no. 1, pp. 45-55, 2009.

[41] V. Inglis, K. Ball, and D. Crawford, "Socioeconomic variations in women's diets: what is the role of perceptions of the local food environment?" Journal of Epidemiology and Community Health, vol. 62, no. 3, pp. 191-197, 2008.

[42] R. Foley, C. Pollard, and D. McGuiness, "Food Cent\$: achieving a balanced diet on a limited food budget," Nutrition and Dietetics, vol. 54, no. 4, pp. 167-172, 1997.

[43] Food Standards Agency, Low Income Diet and Nutrition Survey: Summary of Key Findings, The Stationary Office, London, UK, 2007.

[44] A. Tsang, M. W. Ndung'u, J. Coveney, and L. O’Dwyer, “Adelaide Healthy Food Basket: a survey on food cost, availability and affordability in five local government areas in metropolitan Adelaide, South Australia," Nutrition and Dietetics, vol. 64, no. 4, pp. 241-247, 2007.

[45] K. Ball, A. Timperio, and D. Crawford, "Neighbourhood socioeconomic inequalities in food access and affordability," Health and Place, vol. 15, no. 2, pp. 578-585, 2009.
[46] K. Järvelä, J. Mäkelä, and S. Piiroinen, “Consumers' everyday food choice strategies in Finland," International Journal of Consumer Studies, vol. 30, no. 4, pp. 309-317, 2006.

[47] G. Enticott, "Risking the rural: nature, morality and the consumption of unpasteurised milk," Journal of Rural Studies, vol. 19, no. 4, pp. 411-424, 2003.

[48] J. M. Green, A. K. Draper, and E. A. Dowler, "Short cuts to safety: risk and 'rules of thumb' in accounts of food choice," Health, Risk and Society, vol. 5, no. 1, pp. 33-52, 2003.

[49] K. Glanz, M. Basil, E. Maibach, J. Goldberg, and D. Snyder, "Why Americans eat what they do: taste, nutrition, cost, convenience, and weight control concerns as influences on food consumption," Journal of the American Dietetic Association, vol. 98, no. 10, pp. 1118-1126, 1998.

[50] D. Neumark-Sztainer, M. Story, C. Perry, and M. A. Casey, "Factors influencing food choices of adolescents: findings from focus- group discussions with adolescents," Journal of the American Dietetic Association, vol. 99, no. 8, pp. 929-937, 1999.

[51] P. Rozin, C. Fischler, S. Imada, A. Sarubin, and A. Wrzesniewski, "Attitudes to food and the role of food in life in the U.S.A., Japan, Flemish Belgium and France: possible implications for the diethealth debate," Appetite, vol. 33, no. 2, pp. 163-180, 1999.

[52] K. Roininen, H. Tuorila, E. H. Zandstra et al., "Differences in health and taste attitudes and reported behaviour among finnish, Dutch and British consumers: a cross-national validation of the Health and Taste Attitude Scales (HTAS)," Appetite, vol. 37, no. 1, pp. 33-45, 2001.

[53] P. Ward, L. Mamerow, J. Henderson, A. W. Taylor, S. B. Meyer, and J. Coveney, "The social determinants of food purchasing practices: who chooses price-before-health, taste-before-price, or organic foods in Australia?" Food and Nutrition Sciences, vol. 3, pp. 461-470, 2012.

[54] Queensland Health, The 2000 Healthy Food Access Basket (HFAB) Survey: Full Report, Queensland Government, Brisbane, Australia, 2001.

[55] P. Williams, J. James, and J. Kwan, “The Illawarra Healthy Food Price Index 2: pricing methods and index trends from 20002003," Nutrition and Dietetics, vol. 61, no. 4, pp. 208-214, 2004.

[56] P. Williams, M. Reid, and K. Shaw, “The Illawarra Healthy Food Price Index 1: development of the food basket," Nutrition and Dietetics, vol. 61, no. 4, pp. 200-207, 2004.

[57] Department of Health and Community Services, NT Market Basket Survey 2007, Northern Territory Government, Darwin, Australia, 2007.

[58] J. Meedeniya, A. Smith, and P. Carter, Food Supply in Rural South Australia: A Survey on Food Cost, Quality and Variety, South Australian Government, Adelaide, Australia, 2000.

[59] National Health and Medical Research Council, Recommended Dietary Intakes for Use in Australia, NHMRC, Canberra, Australia, 1991.

[60] C. Palermo and A. Wilson, "Development of a healthy food basket for Victoria," Australian and New Zealand Journal of Public Health, vol. 31, no. 4, pp. 360-363, 2007.

[61] Australian Bureau of Statistics, Family Characteristics, Australia, June 2003, ABS, Canberra, Australia, 2004.

[62] Australian Bureau of Statistics, Census of Population and Housing, ABS, Canberra, Australia, 2009.

[63] Department of Health and Ageing and National Health and Medical Research Council, Nutrient Reference Values for Australia and New Zealand, Commonwealth of Australia, Canberra, Australia, 2006. 
[64] C. E. Palermo, K. Z. Walker, P. Hill, and J. McDonald, “The cost of healthy food in rural Victoria," Rural and Remote Health, vol. 8, no. 4, p. 1074, 2008.

[65] Australian Bureau of Statistics, Household Income and Income Distribution, Australia, 2005-06, ABS, Canberra, Australia, 2007.

[66] Australian Bureau of Statistics, Labour Price Index-March Quarter 2009, ABS, Canberra, Australia, 2009.

[67] P. Williams, A. Hull, and M. Kontos, "Trends in affordability of the Illawarra Healthy Food Basket, 2000/2007," Nutrition \& Dietetics, vol. 66, no. 1, pp. 27-32, 2009.

[68] J. Disney, Affordable Housing in Australia: Some Key Problems and Priorities for Action, National Forum on Affordable Housing, Australian Housing and Urban Research Institute, Melbourne, Australia, 2007.

[69] J. Yates and M. Gabriel, Housing Affrodability in Australia, Australian Housing and Urban Research Institute, Sydney, Australia, 2006.

[70] Australian Council of Social Services, Submission to the Senate Inquiry into Housing Affordability, ACOSS, Sydney, Australia, 2007.

[71] South Australian Council of Social Services, Cost of Living Biannual Update, No. 2, SACOSS, Adelaide, Australia, 2009.

[72] A. Drewnowski and A. Barratt-Fornell, "Do healthier diets cost more?” Nutrition Today, vol. 39, pp. 161-168, 2004.

[73] A. Drewnowski and N. Darmon, "The economics of obesity: dietary energy density and energy cost," The American Journal of Clinical Nutrition, vol. 82, no. 1, pp. S265-S273, 2005.

[74] C. Ni Mhurchu, T. Blakely, Y. Jiang, H. C. Eyles, and A. Rodgers, "Effects of price discounts and tailored nutrition education on supermarket purchases: a randomized controlled trial," American Journal of Clinical Nutrition, vol. 91, no. 3, pp. 736-747, 2010.

[75] A. Hillier, C. Cannuscio, A. Karpyn, J. Mclaughlin, M. Chilton, and K. Glanz, "How far do low-income parents travel to shop for food? Empirical evidence from two urban neighborhoods," Urban Geography, vol. 32, no. 5, pp. 712-729, 2011.

[76] L. A. O’Dwyer and J. Coveney, "Scoping supermarket availability and accessibility by socio-economic status in Adelaide," Health Promotion Journal of Australia, vol. 17, no. 3, pp. 240-246, 2006.

[77] T. Pearson, J. Russell, M. J. Campbell, and M. E. Barker, "Do 'food deserts' influence fruit and vegetable consumption?-a cross-sectional study," Appetite, vol. 45, no. 2, pp. 195-197, 2005.

[78] A. Whelan, N. Wrigley, D. Warm, and E. Cannings, "Life in a 'food desert,' Urban Studies, vol. 39, no. 11, pp. 2083-2100, 2002.

[79] M. White et al., "Do 'food deserts' exist?" European Journal of Public Health, vol. 14, no. 4, p. 34, 2004.

[80] N. Wrigley, "Food deserts' in British cities: policy context and research priorities," Urban Studies, vol. 39, no. 11, pp. 2029-2040, 2002.

[81] N. Wrigley, D. Warm, B. Margetts, and A. Whelan, "Assessing the impact of improved retail access on diet in a 'food desert': a preliminary report," Urban Studies, vol. 39, no. 11, pp. 2061-2082, 2002.

[82] M. Harrison, A. Lee, M. Findlay, R. Nicholls, D. Leonard, and C. Martin, "The increasing cost of healthy food," Australian and New Zealand Journal of Public Health, vol. 34, no. 2, pp. 179-186, 2010.
[83] A. S. Anderson, J. Dewar, D. Marshall et al., “The development of a healthy eating indicator shopping basket tool (HEISB) for use in food access studies-identification of key food items," Public Health Nutrition, vol. 10, no. 12, pp. 1440-1447, 2007.

[84] S. Cummins and S. Macintyre, "A systematic study of an urban foodscape: the price and availability of food in greater Glasgow," Urban Studies, vol. 39, no. 11, pp. 2115-2130, 2002.

[85] C. Ni Mhurchu and S. Ogra, "The price of healthy eating: cost and nutrient value of selected regular and healthier supermarket foods in New Zealand," New Zealand Medical Journal, vol. 120, no. 1248, 2007.

[86] P. Monsivais, J. Mclain, and A. Drewnowski, "The rising disparity in the price of healthful foods: 2004-2008," Food Policy, vol. 35 , no. 6, pp. 514-520, 2010. 


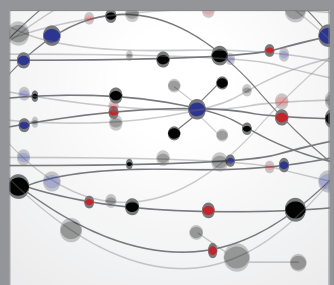

The Scientific World Journal
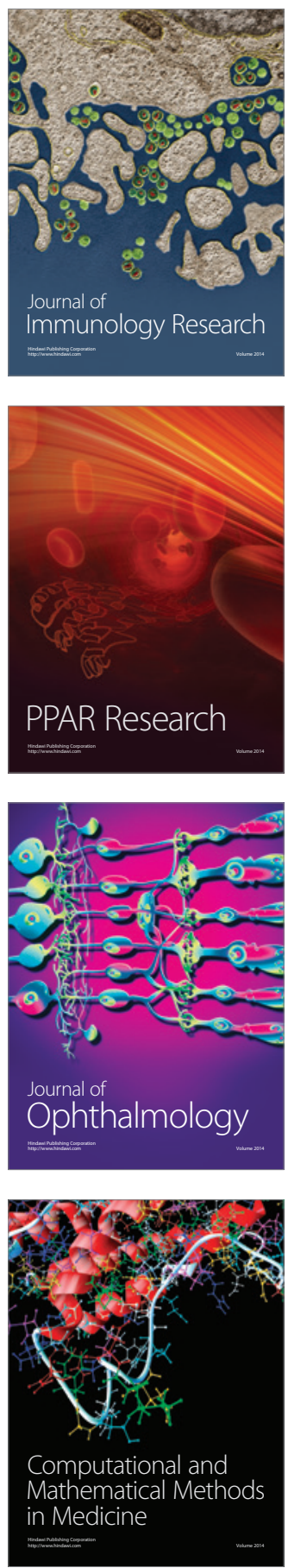

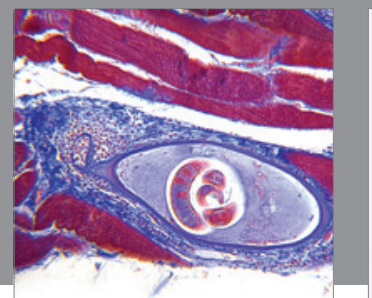

Gastroenterology

Research and Practice
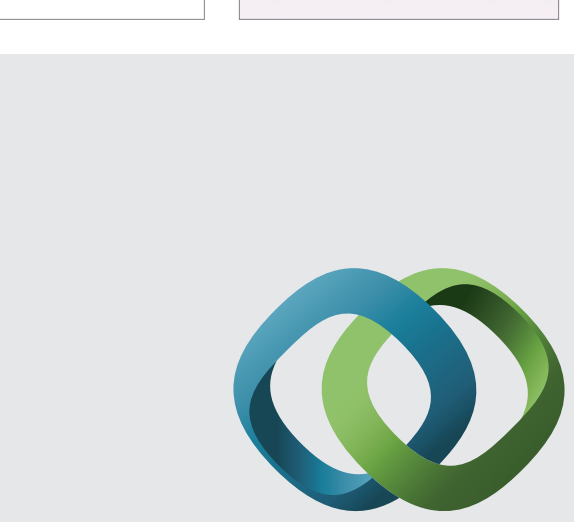

\section{Hindawi}

Submit your manuscripts at

http://www.hindawi.com
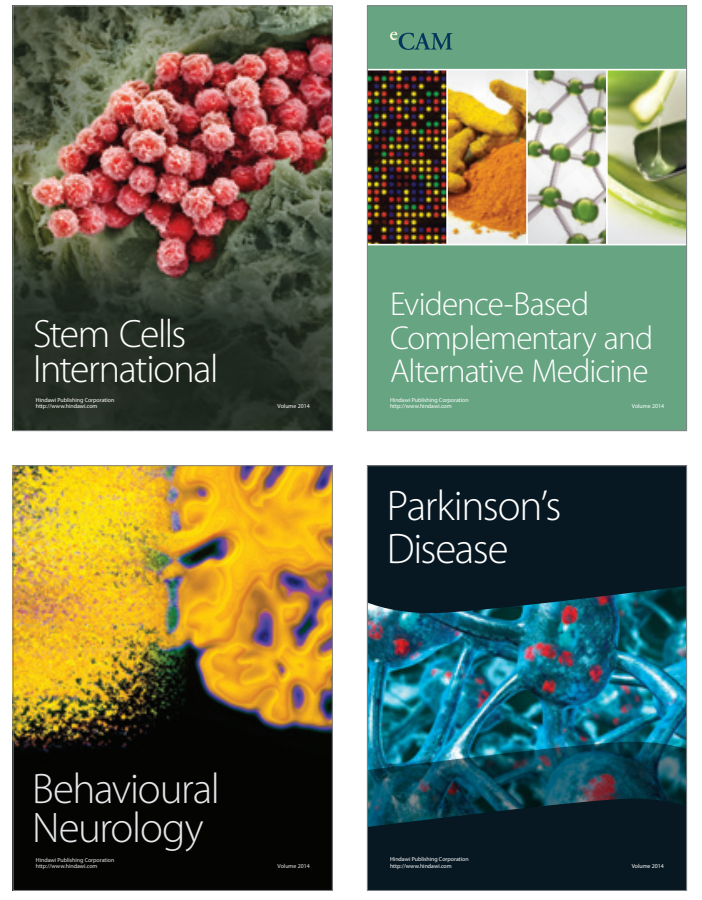
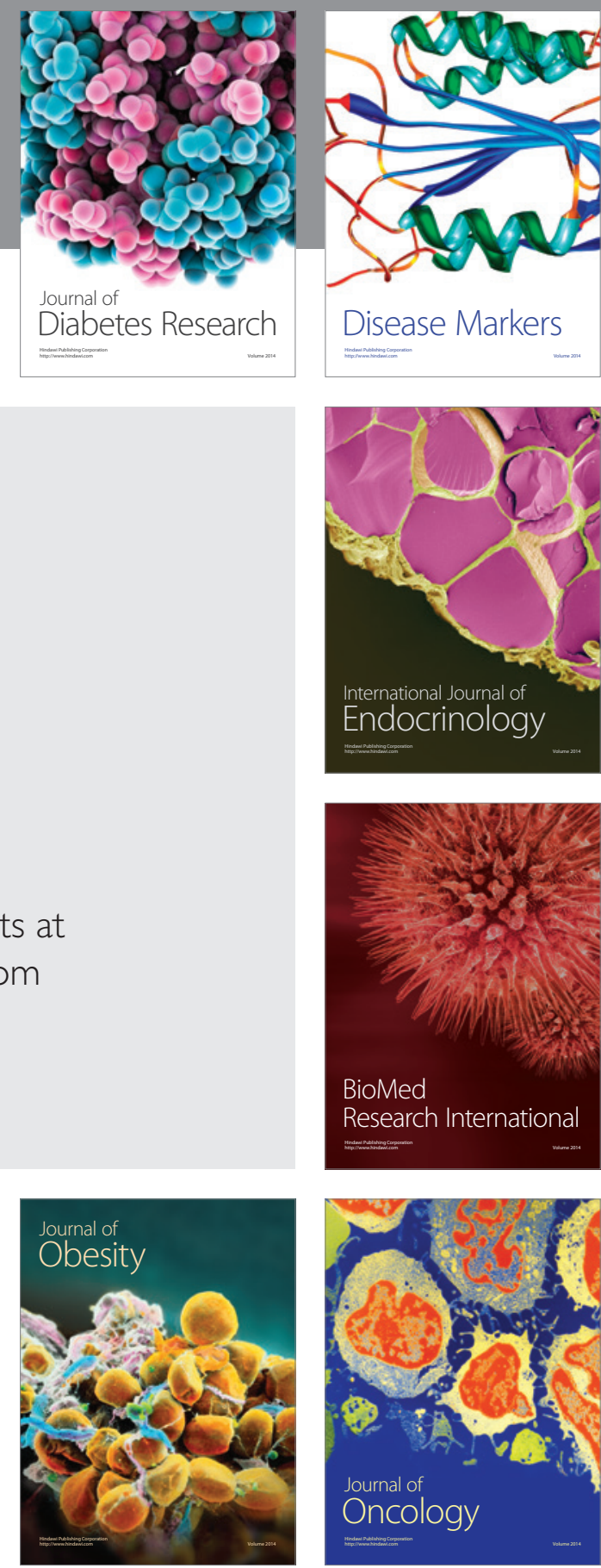

Disease Markers
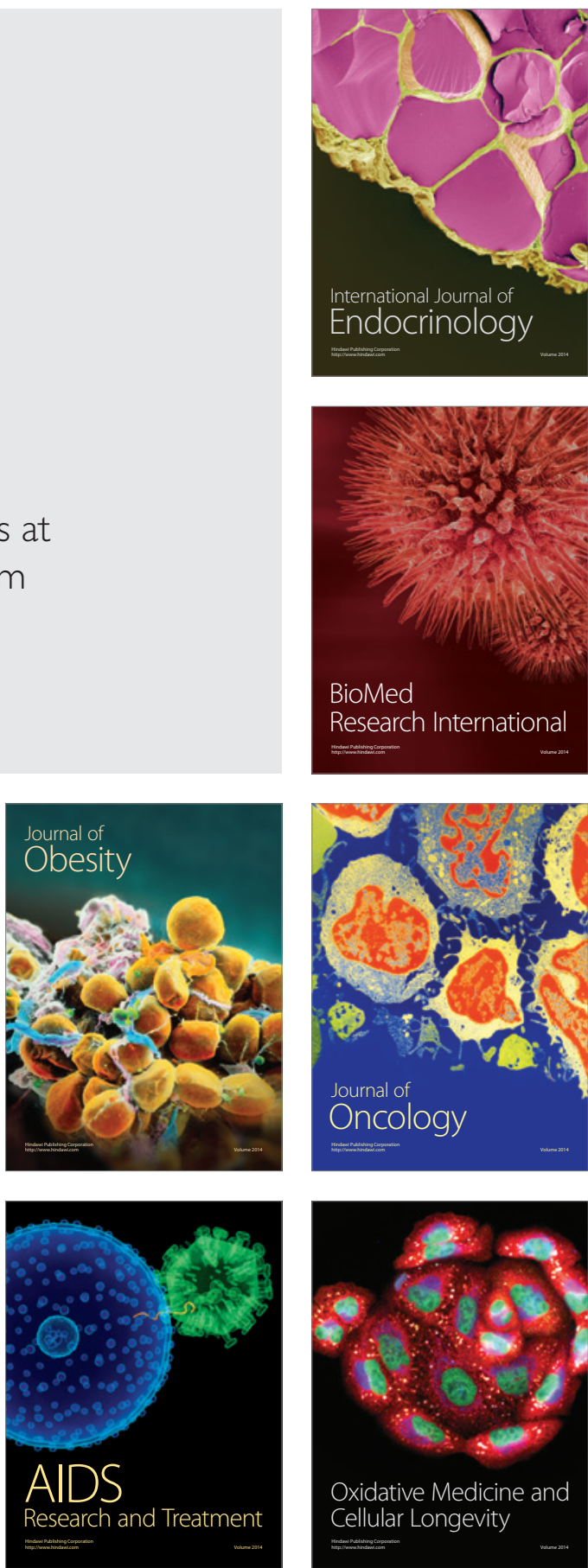